\title{
A Study on the Analysis of Garden Elements in Rural Community Resting Areas
}

\author{
Mee Jeong Park, Hyun Seung Chin*, and Bo Bae Jeon \\ National Institute of Agricultural Science, RDA, Wanju 55365, Korea
}

\begin{abstract}
During recent decades, considerable amount of attention and resources have been invested to promote community vitalization and develop areas that are suitable for gardening in close proximities to cities. Frequent occurrences and wide-spread public events based on the gardening theme today such as garden show are prominent examples of such social tendencies. However contrarily to popular beliefs, such efforts have been very marginally realized in rural areas, in which tools and natural elements necessary for growing and cultivating plants are already in place. In reality, production-oriented life-style in modern rural society has degraded recreational aspects of living standards of rural habitants. And thus, implementation of the gardening space holds important merit and is a necessity to vitalize community in rural areas. In this work, we performed an extensive survey on rural community resting area garden elements that were previously established since 1990s. In particular, we look into garden elements of whether functionalities of such facilities are adequate to provide suitable gardening spaces. This manuscript consists of two major parts (1) identifying constituent elements for gardens and (2) analysis of garden elements in existing community resting areas for its conversion to a community garden. Ultimately, identifying necessities for gardening and finding proper locales are two of the most important steps in implementation community garden in rural areas. As the result, rural community resting area is proper to community garden because most of them has a good accessibility. But garden elements improvement such as flower bed except for convenience facilities and plants planning for four season garden is needed for improving the resting area.
\end{abstract}

Key words: facility, garden, garden elements, plant, rural village

\section{I . Introduction}

With complexity, urbanization and mechanization of the society, the living spaces of contemporary people who are suffering from unlimited competitions and excessive stress are rapidly transforming themselves to the artificial environment from the nature-oriented one, causing a growing demand for healthy and happy living in a comfortable and safe environment originally oriented to the nature (Kim, 2013). In practice, many city parks have been built to satisfy the needs of city dwellers, and the garden-themed events such as International Garden Exposition Suncheon Bay Korea 2013 and Korea Garden Show appeared to reflect such interests and desire of city dwellers.

Received on September 21, 2015. Revised on December 21, 2015. Accepted on December 24, 2015.

*Comesponding author: chin.hs@korea.kr

This research was conducted under the research project (project number: PJ01009801, PJ01009802) of National Institute of Agricultural Science, RDA in 2015.
Recently, the gardening activities have been focused on as a key alternative to establishing and recovering the local communities since gardens are where the green spaces are created, the leisure and cultural activities are performed and communications are made, and some researches are currently being conducted on establishment of the communities (Ahn, 2006; Lim and Lee, 2011; Lee and Son, 2014; Park 2012; Roh, 2012). Local governments and relevant agencies are promoting the community building projects based on gardens and volunteer works, expositions and exhibitions under the theme of the gardening activities. In addition, there are an increasing number of organizations operating the 'gardener training program', which grants the city dwellers qualifications for becoming a city gardener by offering gardening classes, and in many cases, the residents are participating in the community regeneration activities to create the community resting areas or gardens.

Gardens are the 'place that integrates the worlds of inner and external side' (Winicott, 1971). English landscape architect, Search (2001) said that 'gardens are the driving force to 
comfort ourselves and develop our creativity, and especially the oriental gardens make us to take a break from thinking, to calm ourselves and to recognize that we can see more by emptying our minds' in his book titled "Healing Garden".

It is easy to believe that the residents of the rural communities have a higher emotional stability and comfortability compared to the city dwellers but the reality that has to only prioritize economic gains from workforce is gradually decreasing the quality of life of the full-time farmers. Although it may be argued that the parks mentioned in the cities are not necessary in rural areas which are composed of the natural elements, a part of the relatively poor quality of life in rural communities can be seen as a lack of spaces where the residents can use their spare time. Therefore, it is one of the matters to be first considered to create spaces for vitalizing the use of rural residents' spare time and the village communities in promoting the environmental improvement projects in rural areas (Lee, 1996). It can be an alternative to use the community resting areas in rural communities as a garden to improve the landscape of the rural communities and for the residents to spend their free time.

Lim (2000) defined a garden as 'something that bought the nature into the architectural space by planting trees, beautiful flowers and grasses and making ponds in the yard', and 'in a broad sense, it means the whole space where the plants are planted and in a narrow sense, it is a space in the form of nature additionally decorated by structures and sculptures as needed by artificially placing the trees and flower plants for ornamental and gardening purposes'. In other words, the community resting areas in rural communities can be regarded as gardens with trees, beautiful flowers and sculptures.

By piecing together the definitions of community resting areas discussed in the advanced researches on the community resting areas in rural communities (Lee, 1996; Kim, 1999; Cho, 2002; Gyeonggi Agricultural Research \& Extension Services, 2003), it is considered that the community resting areas in rural communities are one of the parks established for relaxation and the leisure activities for the residents, provide leisure spaces to the residents by introducing the artificial amenities in the spaces dominated by the elements of the nature and have meaning as a central and symbolic space of the rural communities. The resting areas can also be referred to the spaces where the residents can use their spare time and improve a sense of fellowship, and the indigenous natural environment of rural areas, culture of community, living environment and traditional culture are maintained and preserved. Although the research on satisfaction of the residents for the community resting areas of rural communities and the state of the facilities (Lee, 1996; Park, 2005) was conducted, there were few researches on the usage behavior of the areas as a community garden or improvement directions.

Therefore, this study aimed to provide the resting areas to the rural residents as a community garden and improve their quality of life such as emotional satisfaction and mental health by analyzing the elements of the community gardens of rural communities, and suggest the matters to be improved and supplemented to reuse the areas as a means of revitalizing communities through the gardening activities.

\section{Research method}

\section{Research subjects}

The research aimed to identify whether the community resting areas which are playing a pivotal role in village communities have the elements for the gardening activities to create community gardens for rural communities. Therefore, this study intended to develop the survey form by coming up with the elements to create the gardens through advanced researches, and identify the gardening elements of community resting areas after analyzing the results of the research on the actual community resting areas in rural communities.

To that end, the research targeted each community resting area of 8 cities and guns except for the Jeju Island (Table 1). The research nominated 40 communities operating the flower festivals and flower-related experiences among the resort towns in farming and fishing communities or agricultural traditional thematic communities as a candidate to select the communities for the research. The research was conducted by a team of four specialists with a master's degree or higher of science of landscape architecture from August to October 2014, and conducted an actual survey on the space structure and conditions of the gardens through the on-site survey.

The data was collected through the on-site survey on the 
Table 1. Study sites.

\begin{tabular}{cc}
\hline Site & Study sites \\
\hline A & Gyeeonggi Anseong-si Daeduck-myeon Sonae-ri \\
B & Gangwon Hongcheon-gun Seo-myeon Mogok-ri \\
\hline C & Chungbuk Eumsung Soi-myeon Gapsan-ri \\
\hdashline D & Chungnam Taean-gun Sowon-myeon Beopsan-ri \\
\hline E & Jeonbuk Jinan-gun Jinan-eup Yeonjang-ri \\
\hline F & Jeonnam Yeongam-gun Gunseo-myeon Donggurim-ri \\
\hdashline G & Gyeongbuk Gyeongju Angang-eup Oksan-ri \\
\hdashline H & Gyeongnam Miryang Chodong-myeon Bonghwang-ri \\
\hline
\end{tabular}

Table 2. Location and plan view of the rest area site.

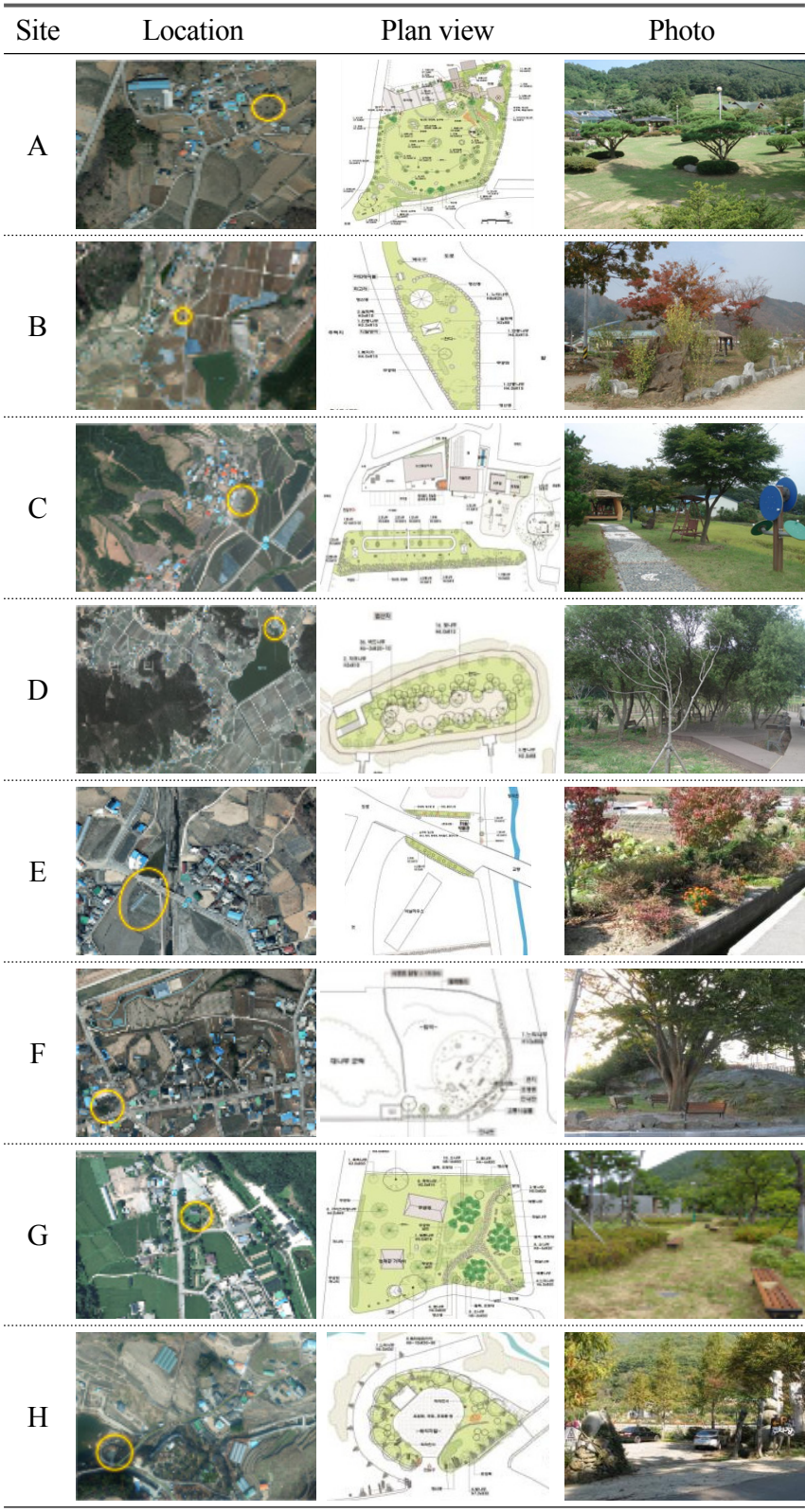

conditions of the community environment and surrounding areas of the community resting areas, and the forms and accessibility of the community resting area property. The location map, floor plan and photos of the community resting areas researched through the blueprint and on-site survey are shown in Table 2. The villages with the resting area located at the entrance are $\mathrm{C}, \mathrm{D}, \mathrm{F}$ and $\mathrm{H}$ and the villages with the resting area located at the center are A, B and G. In addition, the resting area of village $\mathrm{E}$ was located inside the village.

\section{Design of survey form}

The research analyzed and reclassified the surveyed items of the advanced researches on the analysis of preference for garden design or the analysis of satisfaction for the garden elements (Ahn, 2004; Jung, 2004; Lee and Kim, 2007; Park et al., 2008; Hong, 2011; Jeon et al., 2011; Kim, 2012; Kim et al., 2012; Kim et al., 2013; Shin et al., 2011) to figure out the garden elements of community resting areas and designed the on-site survey form. The surveyed items of the advanced researches are divided into outdoor and indoor garden types, including accessibility, motivation of visit, facility, plant management, function and environment and resting area. They are classified into location type and form, size, accessibility, facilities and plants according to the reclassification by the characteristics of the surveyed items. A total of 14 detailed items customized to the on-site survey of rural communities were produced (Table 3 ).

\section{Conclusion and considerations}

\section{Location type and form}

The location types of 8 community resting areas were

Table 3. Survey items.

\begin{tabular}{|c|c|}
\hline Category & Survey items \\
\hline Location type & Location type, land shape, usage type \\
\hline Size & Area, community resting area per household \\
\hline Accessibility & $\begin{array}{c}\text { Distance from village entrance, distance from village } \\
\text { center, distance form residential areas }\end{array}$ \\
\hline Facilities & Resting, landscape, scenery, convenience \\
\hline Plant & Tree, bush, flowers \\
\hline
\end{tabular}


divided into detached type located independently and public facility type located within the public facility site. The detached type includes the type of using the space underneath the pavilion tree. There were various forms of spaces within the site of the village hall in Village $C$, as it built the rice grinding mill, playground and sports park within the site. The resting areas were in the polygon, linear and circular forms and the one at Village $\mathrm{E}$ was in the indefinite form with the trail and the lotus garden. When it comes to the usage of the resting areas, the resting areas were mostly used just as a resting area, and sometimes in various forms, such as sports park, parking area and the area with observatory and landscape. This way, it is required to determine the size of the gardening elements depending on the location type and site shape in designing gardens and select the elements depending on the usage behavior so that the resting areas that are used just as a resting area can be improved to be the space with enhanced landscapes and ornamental garden after supplementing the gardening elements.

Table 4. Type and form of surveyed areas.

\begin{tabular}{ccccc}
\hline Site & Location type & Land shape & Usage type \\
\hline A & Standalone & Polygon & Resting area \\
\hdashline B & Standalone & Linear & Resting area \\
\hdashline C & Public facility & Polygon & Exercising \\
\hdashline D & Standalone & Circular & Observatory \\
\hline E & Standalone & Undetermined form & Positive landscape \\
\hdashline & Standalone & Polygon & Resting \\
F & (under a shade tree) & & \\
\hdashline G & Standalone & Polygon & Resting \\
\hdashline H & Standalone & Circular & Parking space \\
\hline
\end{tabular}

Table 5. Size of resting area.

\begin{tabular}{ccccc}
\hline Site & $\begin{array}{c}\text { People } \\
\text { population }\end{array}$ & $\begin{array}{c}\text { Household } \\
\text { number }\end{array}$ & $\begin{array}{c}\text { Area } \\
\text { (py.) }\end{array}$ & $\begin{array}{c}\text { Area per } \\
\text { household (py.) }\end{array}$ \\
\hline A & 172 & 61 & 601 & 9.85 \\
\hdashline B & 200 & 90 & 101 & 1.12 \\
\hdashline C & 103 & 57 & 1,445 & 25.35 \\
\hline D & 280 & 200 & 536 & 2.68 \\
\hline E & 99 & 50 & 1,058 & 21.16 \\
\hdashline F & 1,128 & 504 & 251 & 0.49 \\
\hdashline G & 134 & 65 & 815 & 12.53 \\
\hdashline H & 40 & 25 & 151 & $6 . .$. \\
\hline
\end{tabular}

\section{Size and accessibility}

According to the research on size, the resting areas were sized from 101 pyeong $\left(333.9 \mathrm{~m}^{2}\right)$ to 2,404 pyeong $\left(7,947.1 \mathrm{~m}^{2}\right)$. The analysis on the size of the resting area per household to figure out the appropriate size of the community resting areas against the number of population of the villages discovered a high deviation in the size of the resting area per household from 0.49 pyeong to 25.35 . pyeong. Village $\mathrm{C}$ had the widest resting area sized approximately 1,400 pyeong, and about 25 pyeong sized resting area per household, which was a high figure. In mostly populated Village $\mathrm{F}$, the size of the resting area per household was less than 1 pyeong.

To analyze accessibility, the research measured the distance and walking time between the entry of the village, the village hall and the residential area and the resting areas. The resting areas were in a minimum 1 minute to maximum 14 minute distance on walk from the entry of the village, in a 1 minute to 3 minute distance from the village hall and in a 1 minute to 23 minute distance from the residential area, showing that the resting areas were mostly close to the village hall in an average 6.9 minute walling distance (Table 6). Since the village hall is the space which is the most important to the residents of the rural communities and where the residents spend the longest time during the daily schedule, such a high accessibility to the

Table 6. Accessibility of resting area.

\begin{tabular}{|c|c|c|c|c|c|c|c|c|}
\hline \multirow{3}{*}{ Site } & \multirow{2}{*}{\multicolumn{2}{|c|}{$\begin{array}{c}\text { Entrance of } \\
\text { village }\end{array}$}} & \multirow{2}{*}{\multicolumn{2}{|c|}{$\begin{array}{l}\text { Residence } \\
\text { center }\end{array}$}} & \multicolumn{4}{|c|}{ Residential area } \\
\hline & & & & & \multicolumn{2}{|c|}{ Min. } & \multicolumn{2}{|c|}{ Max. } \\
\hline & $\begin{array}{l}\text { Dis.* } \\
(\mathrm{m})\end{array}$ & $\begin{array}{l}\text { W. T. } \\
(\min )\end{array}$ & $\begin{array}{l}\text { Dis. } \\
(\mathrm{m})\end{array}$ & $\begin{array}{l}\text { W. T. } \\
(\min )\end{array}$ & $\begin{array}{l}\text { Dis. } \\
(\mathrm{m})\end{array}$ & $\begin{array}{l}\text { W. T. } \\
(\min )\end{array}$ & $\begin{array}{l}\text { Dis. } \\
\text { (m) }\end{array}$ & $\begin{array}{l}\text { W. T. } \\
(\mathrm{min})\end{array}$ \\
\hline A & 179 & 3 & 138 & 3.0 & 81 & 2.0 & 153 & 3.0 \\
\hline B & 46 & 1 & 200 & 3.0 & 83 & 2.0 & 285 & 5.0 \\
\hline $\mathrm{C}$ & 564 & 9 & 130 & 2.0 & 659 & 10.0 & 246 & 4.0 \\
\hline D & 874 & 14 & 130 & 2.0 & 1,500 & 23.0 & 1,000 & 16.0 \\
\hline $\mathrm{E}$ & 556 & 9 & 160 & 3.0 & 246 & 4.0 & 221 & 4.0 \\
\hline $\mathrm{F}$ & 268 & 5 & 197 & 3.0 & 280 & 5.0 & 193 & 3.0 \\
\hline G & 334 & 6 & 30 & 1.0 & 183 & 3.0 & 173 & 1.0 \\
\hline $\mathrm{H}$ & 17 & 1 & 159 & 3.0 & 378 & 6.0 & 200 & 3.0 \\
\hline Ave. & 355 & 6 & 118 & 2.1 & 426 & 6.9 & 309 & 4.9 \\
\hline Max. & 874 & 14 & 200 & 3.0 & 1500 & 23.0 & 1000 & 16.0 \\
\hline Min. & 17 & 1 & 30 & 1.0 & 81 & 2.0 & 153 & 1.0 \\
\hline
\end{tabular}

* Dis.: Distance, W.T.: Walking time 
resting areas from the village hall is considered to be desirable.

To use the community resting areas as community gardens after improving them, they should be in an appropriate size and be highly accessible from the residents. The community resting areas were well located with a high accessibility from the village hall in the research target village communities. In terms of size, Village $\mathrm{F}$ needs to create gardens by expanding the community resting areas using the surrounding spare spaces or trails.

\section{Facility elements}

There were various facilities in the resting areas. They were classified by usage to figure out the facilities. The facility elements were divided into resting, landscape, scenery and convenience elements and listed by usage forms of the resting areas (Table 7). The usage forms were separated into resting, exercising, observing, positive landscape and parking space elements. Each form was appeared in the single form except for the four simple resting areas.

The research found that the simple research had the outstanding resting and landscape elements among the facility elements, and ponds and treadmills as scenery elements. The sports park and observatory had unique elements such as acupressure road, raft and deck, and benches and pavilions were the most common elements as a resting element of the resting areas.

Therefore, it is necessary to reinforce the resting elements of benches and pavilions as well as the gardening elements, such as flower gardens that can harmonize the resting elements, to make community resting areas suitable for the gardening activities.

\section{Planting}

To figure out the state of planting of community resting areas of rural communities, the shrubs, tall trees and flowering plants in 8 areas were listed by village (Table 8). Village B, C, D, and $\mathrm{E}$ were the flower-themed villages so that it was possible to check the themed flowers of the villages at each resting area. The village communities may select the representative flowers of their community gardens and use them to create the gardens that can be symbolic of the communities. Village B planted althaea, Village C planted sweet cherry, Village D planted sacred lotus in the Beopsanji pond and Village E planted moss pink on a trail.

According to the survey on the state of planting of 8 resting areas from Village A to $\mathrm{H}$, the remarkable plants were Pine

Table 7. Garden facilities.

\begin{tabular}{|c|c|c|c|c|c|c|}
\hline \multirow{2}{*}{ Usage } & \multirow{2}{*}{ Site } & \multicolumn{5}{|c|}{ Facilities } \\
\hline & & Rest & Landscape & Scenery & Convenience & etc. \\
\hline \multirow{4}{*}{ Resting } & A & $\begin{array}{l}\text { Pavilion, low wooden } \\
\text { bench, rocking chair, } \\
\text { table, parasol, bench }\end{array}$ & $\begin{array}{l}\text { Stone mortar, stone, } \\
\text { stone sculpture }\end{array}$ & Pond, deck & $\begin{array}{l}\text { Sports facilities, } \\
\text { lighting, board }\end{array}$ & Fire pot brazier \\
\hline & B & $\begin{array}{c}\text { Pergola, outdoor } \\
\text { table }\end{array}$ & Stone & Treadmill & & \\
\hline & $\mathrm{F}$ & Bench & $\begin{array}{l}\text { Stone wall, roofing } \\
\text { tiled wall }\end{array}$ & & & Memorial stone \\
\hline & G & Bench, pavilion & Boundary stone & & Lighting, board & Memorial stone \\
\hline Exercising & $\mathrm{C}$ & $\begin{array}{l}\text { Bench, low wooden } \\
\text { bench, lookout hut, } \\
\text { rocking chair }\end{array}$ & & & $\begin{array}{l}\text { Acupressure } \\
\text { pavement, sports } \\
\text { facility bin, lighting, } \\
\text { informing stone }\end{array}$ & Swing \\
\hline Observing & $\mathrm{D}$ & Bench & & Observatory deck & $\begin{array}{c}\text { Floating bridge, raft, } \\
\text { lighting }\end{array}$ & \\
\hline Positive Landscape & $\mathrm{E}$ & & Flower bed, stone & Wooden deck & & Vinyal greenhouse \\
\hline Parking space & $\mathrm{H}$ & Pavilion, bench & $\begin{array}{c}\text { Stone tower, } \\
\text { traditional totem pole }\end{array}$ & & $\begin{array}{l}\text { Stage, street lamp, } \\
\text { lighting }\end{array}$ & \\
\hline
\end{tabular}


among the evergreen needle leaf trees, Japanese yew among the evergreen broadleaf bushes, Maidenhair tree and dawn redwood among the deciduous needle leaf trees, cherry tree among the deciduous broadleaf tree, Royal azalea among the deciduous broadleaf bush and Marigold among the flowering plant. There were not huge differences between 8 resting areas in the state of planting, despite the different conditions of area, form and size. This means that community resting areas of village communities have yet to be properly fulfilling the function of ornamental gardens. If the tree species are selected to create gardens by reinforcing the planting in the community resting areas, the planting plan for four-season gardens can also improve the community resting areas to community gardens, other than the evergreen trees.

\section{Summary}

This study is part of the effort to expand the gardening culture of rural communities, aimed to find the community resting areas in rural communities, which are functioning as a community garden and figure out whether the community resting areas are playing a role as a community garden.

The main research findings are summarized as follows: First, the community resting areas in rural communities were located at the entry, center and inside of the villages, and mostly at the entry of the village. In terms of location type, the resting areas were divided into detached and public facility types. The detached type resting areas include the case using the space underneath the pavilion tree. In addition, the resting

Table 8. Garden plants of the community resting area.

\begin{tabular}{|c|c|c|c|c|c|c|c|}
\hline \multirow{3}{*}{ Site } & \multicolumn{3}{|c|}{ Evergreen } & \multicolumn{3}{|c|}{ Deciduous } & \multirow{3}{*}{ Flower } \\
\hline & \multicolumn{2}{|c|}{ Needleleaf } & \multirow{2}{*}{$\begin{array}{c}\text { Broadleaf } \\
\text { Bush }\end{array}$} & \multirow{2}{*}{$\begin{array}{c}\text { Needleleaf } \\
\text { Tree }\end{array}$} & \multicolumn{2}{|l|}{ Broadleaf } & \\
\hline & Tree & Bush & & & Tree & Bush & \\
\hline A & $\begin{array}{l}\text { Pine, nut pine, } \\
\text { hollywood juniper, } \\
\text { Pinus densiflora for. } \\
\text { multicaulis, norway } \\
\text { spruce }\end{array}$ & $\begin{array}{c}\text { Dwarf } \\
\text { japanese yew }\end{array}$ & $\begin{array}{l}\text { Nandina, } \\
\text { boxwood tree }\end{array}$ & $\begin{array}{l}\text { Maidenhair } \\
\text { tree, dawn } \\
\text { redwood }\end{array}$ & $\begin{array}{l}\text { Maple, vanish tree, crape } \\
\text { myrtle, cherry tree, sand } \\
\text { pear pomegranate tree, } \\
\text { flowering cherry }\end{array}$ & Royal azalea & $\begin{array}{l}\text { Chrysanthemum, } \\
\text { marigold, rose }\end{array}$ \\
\hline $\mathrm{B}$ & & & & & Maple, zelkova & $\begin{array}{l}\text { Royal azalea, } \\
\text { althaea }\end{array}$ & \\
\hline $\mathrm{C}$ & Nut pine & $\begin{array}{l}\text { Japanese } \\
\text { yew }\end{array}$ & Boxwood tree & & $\begin{array}{l}\text { Maple, vanish tree, } \\
\text { zelkova, sweet cherry }\end{array}$ & $\begin{array}{l}\text { Royal azalea, } \\
\text { althaea }\end{array}$ & $\begin{array}{c}\text { Marigold, } \\
\text { lance-leaved } \\
\text { tickseed, globe } \\
\text { amaranth, yellow } \\
\text { iris, iris }\end{array}$ \\
\hline $\mathrm{D}$ & & & & & $\begin{array}{c}\text { Crape myrtle, korean } \\
\text { willow cherry tree, zelkova } \\
\text { silk tree, white mulberry } \\
\text { kobus magnolia, retusa } \\
\text { Fringe Tree }\end{array}$ & & $\begin{array}{l}\text { Reed, sacred } \\
\text { lotus }\end{array}$ \\
\hline $\mathrm{E}$ & Juniper & $\begin{array}{l}\text { Japanese } \\
\text { yew }\end{array}$ & & & Kaki & $\begin{array}{l}\text { Royal azalea, } \\
\text { japanese kerria }\end{array}$ & $\begin{array}{l}\text { Chrysanthemum, } \\
\text { moss pink, rose, } \\
\text { sunflower, } \\
\text { marigold }\end{array}$ \\
\hline $\mathrm{F}$ & Pine & & & & Zelkova, pomegranate tree & & \\
\hline G & $\begin{array}{c}\text { Pine, juniper, } \\
\text { oriental arborvitae }\end{array}$ & & Nandina & $\begin{array}{l}\text { Maidenhair } \\
\text { Tree }\end{array}$ & $\begin{array}{l}\text { Crape myrtle, zelkova } \\
\text { chinese scholar tree, retusa } \\
\text { fringe tree japanese } \\
\text { hackberry, yoshino cherry }\end{array}$ & $\begin{array}{c}\text { Royal azalea, } \\
\text { althaea, wind } \\
\text { spindle tree }\end{array}$ & Sasa borealis \\
\hline $\mathrm{H}$ & & & Boxwood tree & $\begin{array}{l}\text { Dawn } \\
\text { redwood }\end{array}$ & Zelkova, cherry tree & Royal azalea & $\begin{array}{l}\text { Fragrant plantain } \\
\text { lily, } \\
\text { chrysanthemum }\end{array}$ \\
\hline
\end{tabular}


areas were mostly used just as a resting area and there were others with various functions as sports park, observatory and parking lot. Second, the community resting areas were located at minimum 1 minute to maximum 14 minute walking distance from the entry of the village and at minimum 1 to maximum 3 minute walking distance from the village hall and at minimum 1 to maximum 23 minute walking distance from the residential area. Since the village hall is where the residents spend the most of the time, such a high accessibility to the resting areas from the village hall is regarded as desirable to increase the use of the resting areas by the residents Third, the facility elements of community resting areas were divided into resting, landscape, scenery and convenience elements and differentiated upon the usage pattern of acupressure trail of sports park and deck of the observatory. There were themed flowers in four resting areas in the flower-themed village communities but no big differences in the state of planting despite the various conditions of region, shape and size.

According to the analysis on such key research findings, the exiting functions and usage pattern by the residents of the community resting areas of rural communities have advantages of easy access by the residents as the resting areas are playing as a community garden and located at a place with high accessibility. However, the fact that most facility elements were for resting and the planting was focusing on evergreen trees with no huge regional differences was identified as an important factor to be supplemented to be used for creating gardens.

The community resting area establishment project, which has been promoted as part of the project to improve the living environment and welfare of the residents of rural communities since 1990s, serves as a good catalyst to improve poor village environment and living environment of rural communities, and gives a positive effect on the environmental improvement of the residential areas and quality living environment. Therefore, it is believed that the community resting areas are enough to function as a community garden and can be positioned as a unique community garden of the village by discovering the themes with distinct characteristics of the region and supplementing gardening planting elements.

Since it is thought that the researcher had a limitation to identifying the detailed characteristics of the communities as an outsider, the future researches should discuss satisfaction of resting areas and necessity for gardening based on the survey on the residents and more detailed and practical researches should be conducted to expand the gardening culture of rural communities.

\section{References}

Ahn, D.S. 2004. Preference analysis for healing garden construction on psychiatric hospital. J. Kor. Insti. Forest Recreation Welfare $8(2): 55-66$

Ahn, C.H. 2006. Agricultural and life is saved by garden community of city. Environment \& Life. 50:35-40.

Cho, S.J. 2002. Rural community facility management. Rural Area and Environment 76:22-28.

Gyeonggi Agricultural Research \& Extension Services. 2003. Rural extension work tutorial.

Hong, J.W. 2011. Components and visitor evaluation of the roof garden. J. Kor. Soc. People Plants Environ. 14(2):117-122.

Jeon, E.J., S.H. Chung, and T.H. Lee. 2011. Revitalization plan of green roof through analysis of demand on green roof user. Kor. Soc. Environ. Administration 17(2):131-140.

Jung, N.R. 2004. Preference analysis for healing garden designs on psychiatric hospitals - Focused on the form of waterscape facilities. MS Thesis, Chonbuk National Univ., Korea.

Kim, C.B. 1999. A study on the user's behavior and satisfaction of the rural - Pocket parks in rural villages around Kyeonggido. MS Thesis, Sungkyunkwan Univ., Korea.

Kim, H., H.K. Kang, K.J. Bang, M.H. Kweon, and S.H. Kim. 2012. User level of preference and satisfaction of rooftop afforestation - Emphasis on office building of Seoul. J. Kor. Soc. People Plants Environ. 15(1):39-46.

Kim, H.S., H.K. Kang, and S.J. Back. 2013. User satisfaction and preference of the hotel roof garden. J. Kor. Soc. People Plants Environ. 16(4):199-207.

Kim, H.Y. 2013. Effects of community garden construction and horticultural activities on the life - Satisfaction of rural residents. PhD Diss., Chungnam Natoinal Univ., Korea.

Kim, S.B. 2012. A research of the residents availability and health effectiveness based upon the types of green roof. J. KILA. 40(3):60-88.

Kim, S.Y., H. Joo, H. Sim, and D. Ahn. 2008. A basic survey for healing garden construction on the elderly nursing hospital, J. Kor. Insti. Forest Recreation Welfare 12(1):11-20.

Lee, S.H. 1996. A study on the rural park planning guide. MS Thesis., Seoul National Univ., Korea.

Lee, A.K. and M.S. Kim. 2007. Preference analysis and plan on indoor kid's garden focused on elementary school students in Seoul and Gyeonggi region. J. Kor. Soc. People Plants Environ. 10(3): 112-118.

Lee, C.H. and Y.H. Son. 2014. The study on community formation 
effect from urban garden management by different operators. J. of Kor. Soc. of Rural Planning 20(1):63-76.

Lim, C.H. 2010. Garden design. Seoul: Namudosi.

Lim, E.J. 2000. Korean view of nature and the formative consciousness indicated in a garden. MS Thesis., Korea National Univ. of Education, Korea.

Lim, M.J. and E.H. Lee. 2011. Users' perception analysis of urban allotments for vitalizing local community. J. Kor. Soc. People Plants Environ. 14(4):237-243.

Park, J.Y. 2005. Characteristics of residents' participation program in design and implementing process of rural villages resting area. MS Thesis., Chonnam National Univ., Korea.

Park, S.H., D.S. Ahn, and C.M. Park. 2008. Analysis on the preference of women on the healing garden. J. Kor. Insti. Forest Recreation Welfare 12(2):11-20.

Park, T.H. 2012. Effects of the urban farm program on the participants' sense of community. MS Thesis., Univ. of Seoul, Korea.

Roh, H.Y. 2012. A study on the influencing factors of urban community garden for the activation of community. MS Thesis., Seoul National Univ., Korea.

Search, G. 2001. The healing garden: Gardening for the mind, body and soul. BBC, London.

Shin, H.C., J.K. Hong, and K.O. Choi. 2011. The analysis of preference for the indoor garden of apartment veranda. J. Kor. Soc. People Plants Environ. 14(6):437-442.

Winicott, D.W. 1971. Playing and reality. John Wiley \& Sons, NY 324. 